Oncología en Imágenes

\title{
Hemoperitoneo en GIST metastásico
}

\author{
B. Cantos, C. Maximiano, A. Hurtado, M. Méndez, R. Cubedo
}

Palabras clave: Tumor del estroma gastrointestinal. GIST. Hemoperitoneo. Metástasis hepáticas.

Varón de 68 años diagnosticado de Tumor del estroma gastrointestinal de intestino delgado (GIST) tratado mediante resección quirúrgica. El tumor medía 12 centímetros, presentaba positividad focal para CD34, y 16 mitosis por campo de 50 aumentos. En el estudio de extensión postquirúrgico se detectaron metástasis suprarrenales bilaterales, hepáticas múltiples y mesentéricas. El paciente inició tratamiento con Imatinib a dosis de $400 \mathrm{mg} /$ día con buena tolerancia. La enfermedad se mantuvo estable hasta marzo de 2006 evidenciandose progresión radiológica de la enfermedad. En ese momento se dobló la dosis de Imatinib a 800 mg/día. Refería edemas y pirosis que se controlaban con Furosemida y antiácidos.

En enero de 2007 el paciente acudió a urgencias por cuadro de dolor abdominal difuso, mareo y pérdida de conocimiento. En la analítica que se realizó se detectó una hemoglobina de 5,7 gr/dl. En ese momento, se realiza un TAC tóraco-abdominal que muestra líquido peritoneal en probable relación con

\section{Oncología, 2007; 30 (3):122-124}

Servicio de Oncología Médica

Hospital Universitario Puerta de Hierro

Madrid (España) sangrado de una lesión ocupante de espacio en segmento VI hepático, de aproximadamente 9 centímetros de diámetro. Múltiples lesiones hepáticas y suprarrenales.

Realizamos embolización de la arteria hepática derecha, consiguiéndose el control del sangrado. Durante el ingreso el paciente presentó frecuentes episodios de broncoespasmo sin respuesta a la medicación instaurada. No existían indicios de sangrado a nivel de la cavidad abdominal pero el enfermo presentó un rápido deterioro de la situación respiratoria certificándose el éxitus a los pocos días del ingreso.

\section{Discusión}

Los tumores del estroma gastrointestinal (GIST) son los tumores mesenquimales más frecuentes del tubo digestivo ${ }^{1}$. Derivan de las células de Cajal o de sus precursoras y hasta en un 30\%-40\% se originan en intestino delgado ${ }^{2}$. Una complicación importante aunque infrecuente de estos tumores es la ruptura del mismo ocasionando un hemoperitoneo. Hasta un $40 \%$ de los pacientes con GIST pueden presentar hemorragia o sangrado a la cavidad abdominal ${ }^{3}$. Son más frecuentes las rupturas del tumor primario, siendo en ocasiones el debut de la enfermedad, lo que origina un hemoperitoneo. Es muy infrecuente, aunque se ha descrito algún caso de hemoperitoneo por ruptura de una metástasis hepática como es el caso expuesto ${ }^{4}$.

El hígado es el lugar más frecuente de metástasis de los tumores del estroma gastrointestinal, con una 

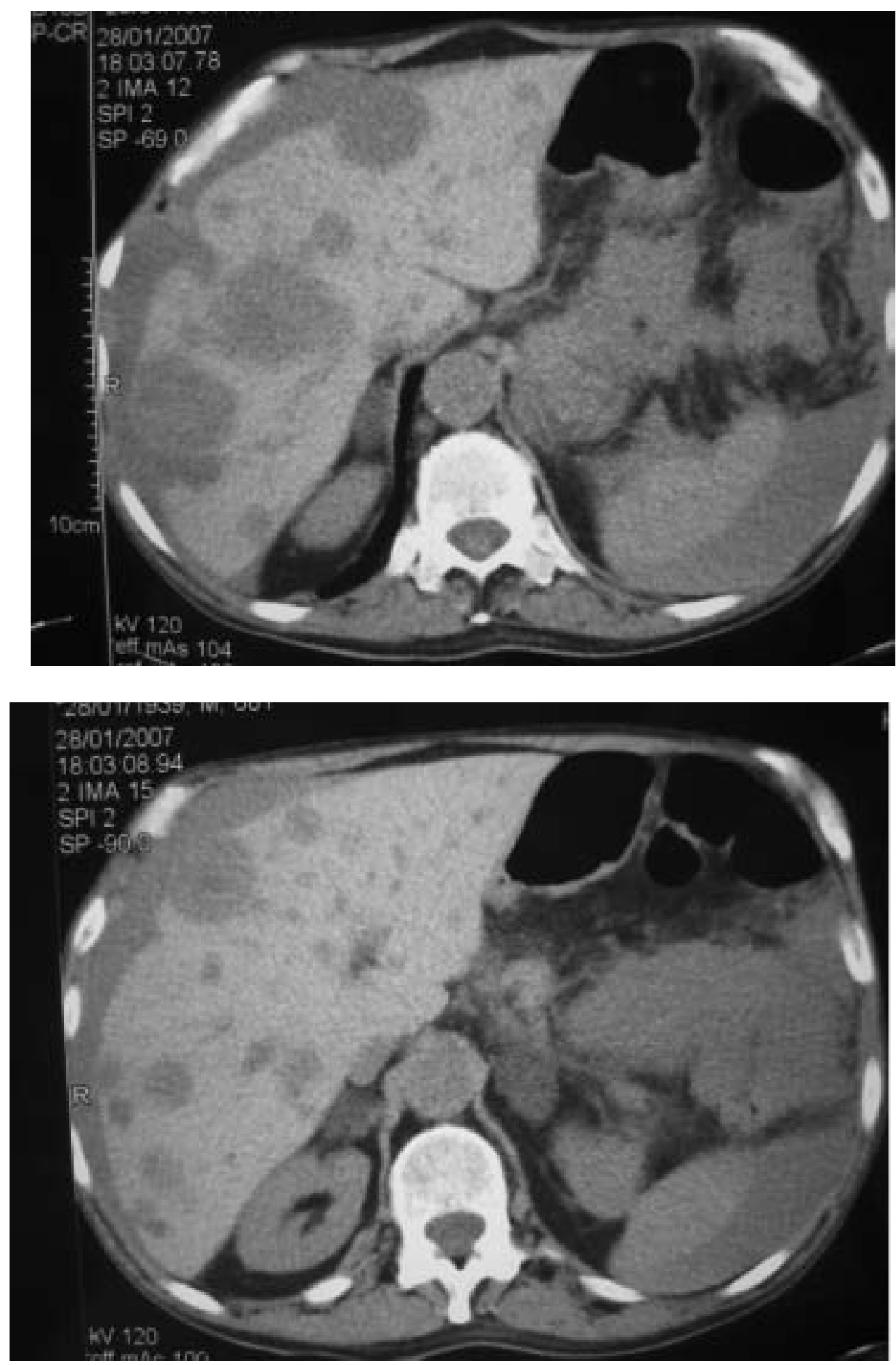

incidencia entre el 55-72\% en los pacientes con recurrencia. En ocasiones se ha empleado la embolización de la arteria hepática como tratamiento para las metástasis hepáticas, aunque en nuestro caso su finalidad era la de controlar el sangrado existente en ese momento ${ }^{5}$. 


\section{B. Cantos y cols.}

\section{Bibliografía}

1. Catalana O, De Lutio di Castelguidone, Nunziata A, Da Rosa V, Sian A. Gastrointestinal stromal tumours: Pictorial review. Radiol Med 2005; 110 (5-6): 484-491.

2. Miettinen M, Lasota J. Gastrointestinal stromal tumors: Pathology and prognosis at different sites. Semin Diagn Pathol 2006; 23(2): 70-83.

3. Tae Hyeon K, Suck Chei C, Chang Soo Choi, Yong-ho Nah. Hemoperitoneum secondary to a ruptured gastric stromal tumor. Gastrointestinal Endoscopy 2006; 63(7): 1066-1067.
4. Cegarra-Navarro MF, De la Calle MA, Girela Baena E, Garcia-Santos JM, Lloret-Estan F, de Andres EP. Ruptured gastrointestinal stromal tumors: Radiologic findings in six cases. Abdom Imaging 2005; 30(5): 535-542.

5. Kobayashi K, Gupta S, Trent JC, Vauthey JN, Krishnamurthy S, Ensor J, Ahrar K, Wallace MJ, Madoff DC, Murthy R, Mcrae SE, Hicks ME. Hepatic Artery chemoembolization for 110 gastrointestinal stromal tumors. Cancer 2006; 107(12): 2833-2841.
Correspondencia:

Dra. B. Cantos Sánchez de Ibargüen

Servicio de Oncología Médica

Hospital Universitario Puerta de Hierro

C/ San Martín de Porres, 4

E-28035 Madrid

bcantos.hpth@salud.madrid.org 